\title{
Meaning of an Ogive by Students of Diploma in Accountancy in an Institute of Higher Education
}

\author{
Sharida Hashim ${ }^{*}$, Nik Azis Nik Pa ${ }^{2}$ \\ ${ }^{1}$ Inovation and Research Unit, Majlis Amanah Rakyat, Kuala Lumpur, Malaysia \\ ${ }^{2}$ Department of Mathematics and Science Education, Faculty of Education, University of Malaya, Kuala Lumpur, Malaysia \\ Email: sharida@mara.gov.my
}

Received October 22, 2013; revised November 22, 2013; accepted November 29, 2013

Copyright (C 2014 Sharida Hashim, Nik Azis Nik Pa. This is an open access article distributed under the Creative Commons Attribution License, which permits unrestricted use, distribution, and reproduction in any medium, provided the original work is properly cited. In accordance of the Creative Commons Attribution License all Copyrights (C) 2014 are reserved for SCIRP and the owner of the intellectual property Sharida Hashim, Nik Azis Nik Pa. All Copyright @ 2014 are guarded by law and by SCIRP as a guardian.

\begin{abstract}
The study based on radical constructivism seeks to identify Semester Two Accounting Courses students' meaning of ogive. Data for this study include verbal and non-verbal information gathered from three students of Semester Two Accounting Courses in clinical interview sessions. The research participants have identified four processes performed on the basic elements to produce an ogive. In addition, five categories of products used by research participants to describe the ogive were identified.
\end{abstract}

\section{KEYWORDS}

Ogive; Meaning in Mathematics; Radical Constructivism; Clinical Interview

\section{Introduction}

Statistics is an important course for most streams at the post-secondary level in higher education institutions. For the Diploma in Accountancy program, statistics is a compulsory course which is made as a condition for graduation [1].

This study is related to statistical learning in post-secondary education. Issues that often arise in statistical learning in post-secondary education relate to student conception of statistics [2-6], the strategies used by students in learning statistics [7-10], and the technology used in the learning of statistics [11-13].

This study focused on accounting diploma students' meaning of ogive. Meaning of ogive is important because it is a complex matter that requires detailed analysis and it can improve thinking and learning statistics. Further, the meaning of ogive cannot be transferred from the thinking of teachers to thinking of students in perfect shape, but the meaning of the ogive is constructed by the students on their own experiences.

So far, the current research in statistical learning in the West focused on several aspects such as conception and understanding of students on some specific aspects of statistics [2,14-17], the strategies used in teaching statistics [7,11], the use of technology in teaching statistics [13], and the difficulties and mistakes of students in learning statistical concepts [18].

Current studies in statistical learning in Malaysia have focused more on the relationship between attitudes and beliefs towards mathematics and statistics [19] and studies on the relationship between ethnic group, gender, trait self-efficacy and effort with the attainment of statistics for the Malay and Chinese undergraduate students [20]. Although there are many studies in the West and a few in Malaysia on statistics by students of higher institution, none have covered the meaning of ogive. The focus of the studies included the mental images or representations of students of sampling, mean, frequency distribution, standard deviation, probability and histogram; there were no studies on the meaning of an ogive.

\footnotetext{
${ }^{*}$ Corresponding author.
} 


\subsection{Theoretical Background}

This study is based on two basic principles [21]. First, knowledge is actively constructed by the students. Second, the reality owned by an individual is a reality built by himself or herself, and it depends on the quality of action and operational schemes of individuals [21].

According to [21-23], there are five assumptions in the radical constructivism of learning ogive: the reality of the ogive to each student is an integral part of the construction of their thinking; knowledge of the ogive is constructed for each student based on his or her experience; knowledge of the ogive is derived from sensory-motor activities and its basic building block is a particular schema; the schema forms mental activity used by students as material for the reflection and abstraction process; and, each intellectual action is built in a progressive manner based on the previous and more primitive cognitive structure.

Based on the above assumptions, for this study, the clinical interview is deemed sufficient to answer the basic questions as described in this study. The clinical interview method consists of observation, questioning and evaluation. This method allows researchers to identify the meaning of the ogive owned by students [21].

\subsection{Objectives and Research Question}

This study aimed at identifying meaning of the ogive held by diploma in accounting students at Institute of Higher Education. Basic questions to be focused in this study are: what is the meaning of the ogive of the Diploma in Accounting students, and what methods are used by students to represent the ogive?

\section{Methodology}

Data for this study were gathered through a clinical interview. The term clinical refers to direct observation of behaviour displayed by the participants while they are solving certain problems in the context of one to one [24]. Participant behaviour observed involved both verbal and nonverbal behaviour. Clinical interviews enable researchers to identify students' meaning and representations on ogive from the student's perspective.

Three research participants for this study, namely Husin, Shazila, and Ali were selected from second semester accounting diploma students. In the course titled introduction to statistics, students are exposed to the topic of statistics during the second semester. Research participants were chosen from the second semester to allow for the scope of the second research question since the ogive is only taught during the second semester. In this activity, research participants were asked to describe the basic elements of the ogive and the process that relate to the formation of the ogive. Then, the participants were asked to give their product of the ogive when the basic elements and the processes were done.

\section{Findings}

This section discusses the findings in three parts, namely the basic elements held by the research participants to form an ogive, the process to form the ogive, and the product used to symbolize the ogive.

\subsection{Meaning of an Ogive}

In general, there are three basic elements to produce an ogive given by the three participants of this study, the information, a statement, or problem basis, and data.

Husin explained that "ogive can be interpreted in the value or price of a thing and doing calculations". He added, "ogive allows one knows a thing or accumulated value of a thing of a common thing".

Husin explained basic element to produce ogive is information, statement or problem basis. He gave several examples of information such as the number of the population, a country race, gender, economic, and crime rates. Further, he stated the other basic elements are samples and sample defines as "a certain number of population studies to be made”. He said two factors are used to produce ogive. He cited two factors, namely the laborers and salaries. Possibility in this case, he had a sense that the information is in the form of non-cumulative data since he gave his opinion without forming table.

Husin explained other basic things that are used to produce ogive is data. He used two types of data, namely in the form of figures and words. He said the figure is the "number of examples" and sample data in the form of the word is "an excuse". He gave the example of the Malaysian population by race, gender, and religion. To give an example of data in numerical form, he formed a frequency table with two columns containing a compilation of words and numbers. He labeled first column with the word "goods" which contained the word car and motor. 
He labelled second column with the words "number of producers" and a collection of numbers.

Husin explained that three processes are performed on the basic element to produce an ogive, which define keywords, marking points, and connect all points freely.

Husin explained that the process is done on the basis of keywords statements assign to two factors for the problem being studied. Husin explained that two factors are identified in the data were to be used in the ogive. He said two factors were used to represent the $x$ and $y$-axis on an ogive. He cited example of the rate of accident on the road. He added that the two factors of the problem is the "type of vehicle" and "kind of way" then, he changed the factors that were the "number of road accidents" and "type of vehicle". He stated that "the number of road accidents" is used to represent the $y$-axis and "type of vehicle" for the $x$-axis. According to him, the data in the table will be used directly after the factors used for the $x$-axis and $y$-axis is determined. He mentioned that the cumulative frequency ogive was a graph.

Husin said he continues to use the data in the table to mark the point on the ogive and form a curve shaped like the letter $S$ starting from the origin. He said, "for the ogive, curve starts from the origin and has an upward curve and eventually dropped a little". In general, Husin focused on the shape of the ogive as an independently connected curve like the letter $S$ starting from the origin. Although he used frequency and not the cumulative frequency to represent the $y$-axis, he used the idea of the ogive shape to connect all the dots without taking into account the actual shape of the graph.

Husin explained that a product of an ogive will be produced after all the basic elements are connected independently starting from the origin, with graph shaped like the letter $S$. He described the drawings by saying "ogive is a cumulative frequency graph".

Shazila mentioned a few elements and used diagrams as a basis for producing ogive. She explained the basic element to produce data for the ogive is used to represent the $x$-axis and $y$-axis.

Shazila expressed data in the form of accumulated data, the frequency table without class intervals and frequency table with class intervals used to produce ogive. When asked the meaning of the table, she said "table contains data that can be used to create graphs".

Shazila explained that frequency tables without a class interval contain two things that are used to represent the $x$-axis and $y$-axis as "the number of people who play" and "kind of game".

Shazila explained that the data collected can be in the form of cumulative frequency of the class interval. The schedule consists of four columns. The first column is labeled with the letter $x$ and the word "number of students", the second column with the letter $f$ and "kind of game", the third column with the letter $F$ and the "cumulative frequency", and the fourth column the words "boundaries". The first column of numbers in the form of a collection of class interval where the initial upper limit of the class interval were re-used as the lower limit of the next class interval, while another column, a collection of numbers.

Shazila explained that five processes are performed on the basic elements to produce an ogive such as calculate the cumulative frequency; calculate the upper boundary; determine the scale and axis; mark the points, and connect the dots.

Shazila explained the process performed on the data in the table. First, she calculated the cumulative frequency and the upper boundary. Shazila explained that cumulative frequency is used for the $y$-axis of the ogive. According to her, the letter $f$ is used to represent the frequency and a letter $F$ for cumulative frequency. She used a frequency table with class intervals to illustrate how to calculate cumulative frequency, which is by adding a frequency with the previous frequency.

Shazila clarified that the boundaries are calculated based on classes interval written in the first column. Next, she wrote in the fourth column with numbers derived from the upper limit of the class interval as the upper boundary for the class. According to her, the set of numbers in a column of cumulative frequencies will be used to represent the $y$-axis and the collection of numbers in the column on the boundaries is used to represent the $x$-axis. She stated the $x$ coordinate represents the "upper boundaries" and $y$ coordinates represent the "cumulative frequency" is used to mark the point on the ogive. When I asked again how to calculate the boundaries, she said that for the class interval $1-5$, the boundaries is 5.5 , which is to add 0.5 to the upper limit of the class and for the class interval $5-10$, the boundaries is 10.5 , by adding 0.5 to 10 . Shazila stated that for the class interval 1 -5 , the boundaries is 5.5 , i.e. by adding 0.5 to the upper limit of the class and for the class interval $5-10$, the boundaries is 10.5 , by adding 0.5 to 10 .

Shazila explained that the next step is to draw the ogive to produce the $x$-axis and $y$-axis. When I asked what method she used to determine the scale, she said she was not sure the way the selection of an appropriate scale. She said, "estimation method is used to determine the scale as long as the scale can accommodate both axis of 
the graph paper". Shazila chose scale using estimation and do not have a specific way to determine the scale.

Shazila stated $x$-axis is labelled with the word "enrolment" and the $y$-axis is labelled with the word "cumulative frequency" after drawing both axes. She expressed the $x$-axis is represented by the upper boundary, but in her actions, she labelled $x$-axis with the words "number of students".

Shazila explained that the point marked on the graph paper by using the small cross. She stated coordinate $x$ represents the upper limit and the $y$ coordinates represents the cumulative frequency. Although, she said the boundary was used to represent the $x$-axis, and the cumulative frequency to represent the $y$-axis, but in her actions, she used a pair of coordinates to represent the upper limit for the $x$-axis and $y$-axis is represented by the cumulative frequency to mark a point on the ogive. After finished marking all points, she connected all points independently to produce an ogive. She did not write the headline for the ogive.

Overall, Shazila have different views about what represents the $x$-axis, the method of calculating the upper boundary, the coordinates used to mark the point, writing headlines, and determine the appropriate scale for the ogive graph. In the context of a mental picture, she stated that the boundaries are used to represent the $x$-axis, but she does not show how to calculate them, instead she used the data directly in the first column in the schedule to represent the $x$-axis, while in the context of the meaning of ogive, in the beginning, she used the limit above the upper boundaries, but when I asked again how to calculate the boundaries, she said the boundaries are obtained by adding 0.5 to the upper limit. Apparently, her views on how to calculate the upper boundary are different.

Shazila view about the $x$-axis to represent the ogive is different in the context of mental representation and meaning of ogive because in the context of meaning of ogive, she stated that the upper boundaries are used to represent the $x$-axis on an ogive, but in the action she used the upper limit, that is the data in the first column of the frequency table to represent the $x$-axis.

In making sense of the ogive, Shazila stated that the basic elements to produce ogive, the process is done on the basis elements, and the products produced after all the basic elements to be done on the ogive.

Shazila explained that the products produced after all the basic elements being done by drawing a graph shaped like the letter $S$ which were connected independently starting from the origin. He described his sketches by stating that "ogive is a graph that has the shape of an upward and downward".

Ali mentioned the basic element that was used to produce ogive was data. He said data is information derived from the studies made. He used the example of the collected data as the basis for producing the element of an ogive.

Ali used the collected data as the basis for producing the element of an ogive. He stated an example of the data was the "price" and "quantity". He said, "price" is used to represent the $y$-axis and "quantity" to the $x$-axis. Next, in his actions, he drew ogive based on the data set to mark a few points and connect the points independently to obtain a curve. He sketched two tables, which are horizontal or vertical and pie charts by using the example of "car number" and the number of users. According to him, the data given in the table will be used directly to produce ogive. He added, "car number" is used to represent the $x$-axis and "number of users" on the $y$-axis. Further, he stated that no additional process performed on the given data to produce ogive. Possibilities in this regard, he noted the boundaries with no cumulative frequency are calculated from the given data.

Ali said three possible processes to produce an ogive, which were: determines the axis, marking the points, and connect the dots independently.

Ali explained that the details of the data will be used to produce an ogive. He stated that the process is done by using the given data sample to draw the ogive. In action, he used "number of users" to represent the $y$-axis and "number of cars" for the $x$-axis. Ali said "number of users" is used to represent the $y$-axis and "number of cars" for the $x$-axis. He stated there was nothing to be done to the data to produce ogive. In this case, I wanted to see if he was counting on the boundary and cumulative frequency, but he said the data is used directly, the "total score" is used to represent the $y$-axis and "number of cars" for the $x$-axis.

Ali explained that the point marked with $x$ coordinates represents "number of cars" and $y$ coordinates represent the "number of users" and all points were connected independently. Ali explained that the data was used to draw the graphs directly. He said, "number of users" is used to represent the $y$-axis and "number of cars" for the $x$-axis. In action, he marked the points with $x$ coordinates represents "number of cars" and $y$ coordinates represent the "number of users". According to him, all the points are connected independently, that is without using a ruler. He explained that "the ruler-shaped graph will be sharp, but an ogive must be shaped like the letter $S$ with the sharp-shaped".

Overall, the outlook of an ogive done by Ali was slightly but not significantly different in verbal, he said ogive is a graph shaped like the letter $S$, but graphically, when in action, he did not get a graph shaped like the 
letter $S$ from the data granted, he said ogive graph does not necessarily like the letter $S$ and depends on the given data. Then, when I ask "what is the ogive?", In his actions, he was drawing a graph on graph paper that is shaped like the letter $S$ that starts from the origin. Apparently, there is a possibility he could not think of a relevant data or he could not figure out the process that must be done on the data to produce the ogive at the time I asked that question.

Ali said the products produced after all the basic elements being done by drawing a graph shaped like the letter $S$ which is connected independently starting from the origin. She described her sketches by stating that "ogive is a graph like the letter $S$ and contains data".

\subsection{Summary}

The focus of this section is to discuss the findings about meaning of the ogive formed by the participants of the study and the implications of this research to teaching.

In making sense of the ogive, the participants of this study indicate the basic elements to produce ogive, process that is done to the basic elements to produce ogive, and a product of all executed process.

Process performed on the basis of things to produce an ogive expressed by the participants of this study involves four categories. The first category for which the process is done on the basis elements to produce an ogive is the first process involves the calculation of cumulative frequency and the upper limit. Process performed on the basis elements to produce an ogive expressed by the participants of this study for the second category involves the first process is the calculation of cumulative frequency and the upper boundary. Process performed on the basic elements to produce an ogive expressed by the participants of this study for the third category involves the first process is the calculation of cumulative frequency and the centre point. The fourth category of processes performed on the basic elements to produce an ogive expressed by participants in the study involves the determination of the first two factors to represent the $x$ and $y$ axis.

The first category for which the process is done on the basic elements to produce an ogive was to calculate the cumulative frequency, the upper limit, mark points using coordinate (lower limit, cumulative frequency), and connect the dots with a ruler.

The second category of processes performed on the basis elements to produce an ogive were to calculate the cumulative frequency, the upper boundary, determine the scale by using the estimation methods, mark points using coordinate pair (upper boundary, cumulative frequency), and connect the dots independently.

The third category of processes performed on the basic elements to produce an ogive were to calculate cumulative frequency, midpoint, determine the $x$ and $y$ axis, mark points using coordinate pair (midpoint cumulative frequency), and connect the dots independently.

The fourth category of processes performed on the basic elements to produce two factors involved in determining the ogive was to represent the $x$ and $y$ axis, mark points using coordinate pairs (in which frequency was used to represent the $x$-axis), and connect the dots independently.

Products produced after all the processes were done on the basic elements to generate the ogive involved five categories; the letter $S$-shaped graph sketch with the points connected independently starting from the origin; letter $S$-shaped graph which was connected with a ruler; graph of a letter $S$-shaped; graph of a reverse letter $S$-shaped, and the bell-shaped graph.

\section{Conclusion}

As a result of interaction with the participants of this study, I found that the meaning of the ogive to each student is an integral part of the construction of their thinking; knowledge of the ogive is constructed for each student based on his or her experience; knowledge of the ogive is derived from sensory-motor activities and its basic building block is a particular schema; the schema forms mental activity used by students as material for the reflection and abstraction process; and, each intellectual action is built in a progressive manner based on the previous and more primitive cognitive structures.

\section{Acknowledgements}

Alhamdulillah, by the name of Allah, most gracious and more merciful, Praised to Allah s.w.t for giving me the faith and opportunity in completing this research.

Most grateful thanks to my advisor, Prof Dr. Nik Azis Nik Pa for his meaningful support, comment, wisdom, encouragement, idea and guidance during this study. His selfless commitment of substantial time and effort to 
this research is sincerely appreciated.

Special thanks to my family especially my beloved husband Yaacob Hamzah and my children for their support and encouragement that give courage and strength for me to success in this research.

To Majlis Amanah Rakyat (MARA), as an employer and sponsor, thank you.

Thank you.

\section{REFERENCES}

[1] Bahagian Pendidikan Tinggi MARA, “Scheme of Work-Statistics,” Unpublished Circular, Kuala Lumpur, 2007.

[2] T. A. Carter, "Knowledge and Understanding of Probability and Statistics Topic by Preservice PK-8 Teachers,” Ph.D. Thesis, Texas A \& M University, Texas, 2005.

[3] R. E. Groth and J. A. Bergner, "Preservice Elementary Teachers' Conceptual and Procedural Knowledge of Mean, Median, and Mode,” Mathematical Thinking \& Learning, Vol. 8, No. 1, 2006, pp. 37-63. http://dx.doi.org/10.1207/s15327833mt10801_3

[4] R. Lehrer, M. J. Kim and L. Schaubble, "Supporting the Development of Conceptions of Statistics by Engaging Students in Measuring and Modelling Variability,” International Journal of Computers for Mathematics Learning, Vol. 12, No. 3, 2007, pp. 195-276. http://dx.doi.org/10.1007/s10758-007-9122-2

[5] P. Petocz and A. Reid, "Something Strange and Useless: Service Students' Conception of Statistics, Learning Statistics and Using Statistics in Their Future Profession,” International Journal of Mathematics Education in Science \& Technology, Vol. 36, No. 7, 2005, pp. 789-800. http://dx.doi.org/10.1080/00207390500271503

[6] L. Saldanha and P. Thompson, “Conceptions of Sample and Their Relationship to Statistical Inference,” Educational Studies in Mathematics, Vol. 51, No. 3, 2003, pp. 257-270. http://dx.doi.org/10.1023/A:1023692604014

[7] K. D. Gardner, “Investigating Secondary School Student’s Experience of Learning Statistics,” Ph.D. Thesis, Georgia State University, Georgia, 2007.

[8] S. M. Lancaster, "Pre-Service Teachers Statistic: Interrelationship between Content Confidence, Knowledge, and Attitude, Pedagogical Content Knowledge; and Teacher Interest in Professional Development in Statistics,” Ph.D. Thesis, University of Oklahama, Oklahoma, 2007.

[9] D. J. Mills, “Students’ Attitudes toward Statistics: Implications for the Future,” College Student Journal, Vol. 38, No. 3, 2004, p. 349.

[10] J. A. Nicholas, "Investigating Secondary Student's Statistics Achievement in Wyoming Schools Utilizing Hierarchial Linear Modeling,” Ph.D. Thesis, University of Wyoming, Wyoming, 2004.

[11] R. L. Kennedy and C. J. McCallister, “Attitudes toward Advanced and Multivariate Statistics When Using Computers,” ERIC Reproduction Service No. ED 464097, 2001.

[12] R. L. Scheaffer, “Statistics for a New Century,” In: M. J. Burke and F. R. Curcio, Eds., Learning Mathematics for a New Centur, NCTM, Reston, 2000, pp. 158-173.

[13] J. D. Schenker, "The Effectiveness of Technology Use in Statistics Instruction in Higher Education: A Meta-Analysis Using Hierarchical Linear Modeling,” Ph.D. Thesis, Kent State University, Kent, 2007.

[14] T. Jacobbe, "Elementary School Teacher's Understanding of Essential Topics in Statistics and the Influences of Assessment Instruments and a Reform Curriculum upon Their Understanding,” Ph.D. Thesis, Climson University, Clemson, 2007.

[15] A. Leavy and N. O’Loughlin, "Preservice Teachers Understanding of the Mean: Moving beyond the Arithmetic Average," Journal of Mathematics Teacher Education, Vol. 9, No. 1, 2006, p. 53. http://dx.doi.org/10.1007/s10857-006-9003-y

[16] M. Meletiou and C. Lee, "Students' Understanding of Histograms: A Stumbling Stone to the Development of Intuitions about Variability,” Sixth International Conference on Teaching Statistics: Developing a statistical Literate Society, Cape Town. In: M. A. Ciancetta, Statistics Students Reasoning When Comparing Distribution of Data. Ph.D. Thesis, Portland State University, Portland, 2003.

[17] L. Saldanha and P. Thompson, “Students’ Scheme-Based Conceptions of Sampling and Its Relationship to Statistical Inference,” Proceeding of the Annual Meeting of the North American Chapter of the International Group for the Psychology of Mathematics Education, Athens, 26-29 October 2002, pp. 1-4.

[18] E. Fishbein and D. Schnarch, "The Evolution with Age of Probabilistic, Intuitively Based Misconception,” Journal for Research in Mathematic Education, Vol. 28, No. 1, 1997, pp. 96-105. http://dx.doi.org/10.2307/749665

[19] J. L. Leong, “High School Students' Attitude and Beliefs Regarding Statistics in a Service-Learning Based Statistics Course,” Ph.D. Thesis, Georgia State University, Georgia, 2007.

[20] A. H. Rosna, "The Effects of State and Trait Worry, Self-Efficacy, and Effort on Statistics Achievement of Malay and Chinese Undergraduates in Malaysia: A Causal Modeling Approach,” Ph.D. Thesis, University of Southern California, Los Angeles, 1999.

[21] E. von Glasersfeld, "Radical Constructivism: A Way of Knowing and Learning,” The Falmer Press, London \& Washington DC, 
1995. http://dx.doi.org/10.4324/9780203454220

[22] N. A. N. Pa, “Children’s Fractional Schemes,” Ph.D. Thesis, University of Georgia, Athens, 1987.

[23] N. A. N. Pa, “Pendekatan Konstruktivisme Radikal Dalam Pendidikan Matematik,” Universiti Malaya, Kuala Lumpur, $1999 b$.

[24] N. A. N. Pa, “Kesepaduan Dalam Pendidikan Matematik,” Non-ISI/Non-SCOPUS Cited Publication, Kementeria Pendidikan Malaysia, Kuala Lumpur, 1996. 